\title{
Interpreting Trust: Abstract and Personal Trust for People Who Need Interpreters to Access Services
}

\author{
by Rosalind Edwards, Claire Alexander and Bogusia Temple \\ London South Bank University; London School of Economics; University of Salford
}

\author{
Sociological Research Online, Volume 11, Issue 1, \\ $<$ http://unw. socresonline.org.uk/11/1/edwards.html> \\ doi:10.5153/sro. 1077
}

Received: 9 Dec 2004 Accepted: 24 Jun 2005 Published: 31 Mar 2006

\begin{abstract}
This article looks at the political and conceptual process of trust drawing on a research project exploring the experiences of people who speak little English and thus need interpreters in order to access services. We examine posited solidarity/diversity tensions in the politicisation of notions of general social trust, and debates about the process of trust, including distinctions between abstract and personal trust, the role of familiarity, and the concept of 'active trust', as well as challenges to the functional link between interpretation and expectation in trust. We address the increasing professionalisation of interpreting service provision based on abstract trust, and use case studies to illustrate the complexity of the articulation of trust in interpreters, often involving personal trust, as well as strategies for managing distrust. We conclude that, while trust may be a personal praxis, it takes place in a particular socio-political context that involves asymmetrical relations that focus on particular, minority ethnic, groups.
\end{abstract}

\section{Keywords: Interpreters, Professionalisation, Solidarity/diversity, Trust}

\section{Introduction}

1.1 The concept of trust has become a feature of recent political discussion and theorisation of the nature of modern society, especially with regard to civic organisation, social integration and social order. While it is treated in a relatively simplistic manner in political discussion, the process of trust is also subject to more subtle academic considerations. In this article we address the process of trust through an analysis of the accounts of people who are in a situation where they are explicitly placing often crucial aspects of their lives in other people's hands - people who speak little or no English and thus need interpreters in order to access services.

1.2 Our aim is two-fold. Firstly, and mainly, we are concerned with an empirical and in-depth demonstration of the contingent and situation-specific processes of trust in the face of theories about the nature of trust that are often discussed in conceptual and allegorical terms only. In particular, we are making a contribution to discussions of trust that attempt to move away from a functionalist approach to its properties towards the actual 'doing' of trust in social and political context. Moreover, we are undertaking this in relation to a substantive field that has received little attention and yet involves a considerable exercise of trust. This brings us to our secondary aim, which is to show how functionalist assumptions about the nature of trust permeate developments in the field of interpreting service provision that bear only a partial relationship to its expression in people who actually use interpreters.

1.3 There is a specific backdrop to this particular exploration of the process of trust, itself concerned with trust in society as a whole. Concerns about the exclusion of some minority ethnic groups from mainstream services and society, and the ability to speak English, have become a highly politicised issue in Britain. Language use currently forms one of the primary targets in the government's rhetoric around 'citizenship', 'community cohesion' and the extent of social trust in public institutions (see, for example, the Denham Report 2001). The ability to speak English has become a key feature of government efforts to ensure shared social trust in public institutions and civic organisations. Where previously 'mother tongue' competence was seen as an integral part of the maintenance of positive minority ethnic community identity, the current policy emphasis is on English language competence and the provision of English language classes as part of integration into British society (Crick Report 2003).

1.4 Linked to this shift are notions that there is a connection between the (non)integration of minority ethnic 
groups into mainstream society and a breakdown of social trust. The Home Office Strength in Diversity consultation document (paragraph 5.1, 2004) states that:

The evidence gathered following the disturbances in Northern English towns in 2001 showed that communities in those places had become segregated, in housing, education, employment and how they spent their leisure time, and that this was one of the factors that had contributed to the breakdown of trust and cohesion.

In response, there have been a plethora of initiatives and policy announcements from central government that centre on 'social cohesion' among people of different races/ethnicities around shared values (Back et al. 2002; Schuster and Solomos 2004).

1.5 Some commentators have taken this argument further. David Goodhart, for example, has argued that the solidaristic, mutual obligations and shared values involved in citizenship are at threat from a 'tipping point' of minority ethnic immigration to the UK, not least because 'the "thickest" solidarities are now found among ethnic minority groups themselves in response to real or perceived discrimination' (2004: 5). In a similar vein, Robert Putnam's recent work on social capital has been concerned with showing how levels of trust and economic equality are lower in communities with greater ethnic diversity. He argues that ethnic diversity is correlated negatively with both inter and intra racial trust, trust and co-operation with neighbours, and trust in local government (2003). Within these views on the state of contemporary society, minority ethnic segregation from mainstream society, into distinct physical, cultural and linguistic enclaves, is seen simply as a choice made by these groups themselves. To use Putnam's terms, they are 'bonding' too much ethnically, and must 'bridge' themselves into social integration and the requirements of citizenship, including through learning to speak English.

1.6 Conceptually, the issue of trust draws our attention to the quality of social relationships between people and the obligations inherent in them (Misztal 1996), here specifically between people who need to access services and the interpreters who they require in order to do so. Trust involves belief about the way that others are likely to behave. In the case of people who need interpreters, trusting someone to act as an interpreter for them involves the belief that the person will understand and correctly translate what they say to someone else and what that third party says back to them, and will keep the information involved in the interaction private. This entails the assumption that the person acting as interpreter is both technically competent to carry out the interpretation and that they are morally committed to the obligation to carry it out and treat it as confidential. Trust also involves an element of uncertainty, however. People who need interpreters take the risk that the person who is interpreting for them may not be able or want to undertake a correct representation of their and other people's words, in circumstances where they may have little ability to monitor the accuracy of the interpretation. They also take the risk that private information will be made public. People may well, therefore, trust some individuals or sorts of people to act as interpreters for them more than others in order to reduce uncertainty and risk. Indeed, as we discuss below, rather than being entirely opposed to each other, risk is part of the constitution of trust in that it is overcome through the process of trusting.

1.7 We begin by looking at some of the relevant features of academic discussion about the functions and constitution of trust, before outlining our research focus and process. We then turn to the accounts of people who need interpreters. We address the issue of the extent to which they are 'trusting' or 'distrustful' people generally, in the light of the posited solidarity/diversity tension noted above. Following this, we move on to our specific exploration of the process of trust in using interpreters to access services. We look at the way that interpreting provision is becoming increasingly professionalised, which contains underlying functionalist assumptions about the qualities that engender trust. We then return to the accounts of people who need interpreters to explore their experiences of using both family and friends, and professional interpreters to access services, using case studies. We also look at the strategies that they employ for managing situations where they do not trust their interpreters. Finally, we draw out our conclusions on the process of trust on the basis of our data.

\section{Trust: Functions and Constitution}

2.1 What exactly constitutes 'trust' and captures its process is a debated issue. As Fran Tonkiss comments, the concept 'frequently operates ... as an analytic shorthand - catching at certain social relations and social norms' (2004, p. 17). As we noted in our introduction, it involves the belief that a person or organisation is capable of, and will act in, a certain way. It is the means of mediating risks in an uncertain situation. There is more to trust than this, however. A key conceptual element of trust is that it can never be complete; it always involves an element of contingency, risk and incomplete knowledge. Complete trust becomes something else conceptually - a habitual expectation of certainty that is termed confidence (Misztal 1996; Tonkiss 2004). In addition, theorists in the field distinguish between different sorts of trust in an effort to pin the concept down. A distinction is often made between the specific trust 
engendered in relationships between individuals in their private or personal relationships, and the generalised trust invoked by professionals, public institutions and contract relationships (including Fox 1974, Frankel 1977, Zucker 1986). In this vein - and important for our discussion of people who need interpreters to access services - Anthony Giddens $(1994,1998)$ refers to 'personal trust' and 'abstract trust'. In relationships that are based on personal trust, comprising bonds such as family or friends, people are assuming that they can rely on these familiar others' consideration of, and stable commitment to, their own needs, interests and preferences. Abstract trust is called upon when a person is not familiar with another party but is reliant on them for their expert knowledge and competence. It is based on impersonal belief that a representative or member of a given expert group or institution will conventionally act according to particular principles, duties and requirements, which are laid down in codes and training for professional groups, rather than their own personal interests.

2.2 Giddens also describes a change in the process of trust in contemporary society, towards people having to exercise 'active trust'. Because contemporary society is characterised by contingency, uncertainty and social differentiation (with the latter regarded as the keystone for the solidarity/diversity tension), our assumptions about how the social world works are increasingly short-lived and constantly subject to change. Such social complexity means that trust has to be actively constructed and experimental, rather than relying on a solid and durable base of social rules. People can no longer just passively exercise trust; rather, they have to actively take a risk and evaluate whether or not to trust (see also Bauman 2000; Beck 1999). Thus, personal trust has come to supplement trust in abstract systems. Yet, as Barbara Misztal points out (1996), there is an increasing need to rely on such systems in a complex modern society.

2.3 Guido Möllering $(2001,2002)$, however, argues that conceptualisation of trust needs to go further than these sorts of preoccupations with its functional properties, (that is a focus on expectations about people's behaviour), or its interpretive foundations, (that is the reasons why people hold those expectations).

Developing Georg Simmel's ideas about a 'further element' in trust ${ }^{[1]}$, he posits a space between the two -between interpretation ${ }^{[2]}$ and expectation; it is the space itself that constitutes trust. There is no automatic logic connecting interpretation (reasons to trust - for example, this is a trained interpreter, or this is my longstanding friend) and expectation (outputs of trust - for example, I trust this person to interpret for me). Trust is the mental process, which Möllering refers to as 'suspension', that allows people to move from interpretation to expectation; that is, a leap of faith that 'brackets out uncertainty and ignorance, thus making interpretive knowledge momentarily certain and enabling a leap to favourable (or unfavourable) expectation' (Möllering 2002, p.2). In both abstract trust (which Möllering refers to as 'institutional trust') and personal trust (or 'traditional trust' in Möllering's terms), familiarity forms the basis for this suspension or leap - in the first case, familiarity with the generic validity of the principles, duties and requirements of the system and the categorical role within it, and in the second, familiarity with the qualities of the specific person/people involved. In both cases, suspension involves habitual and automatic leaps of faith, and risk is thus subjectively low. This is akin to Giddens' passive exercise of trust.

2.4 In situations where there is a lack of familiarity, as Giddens argues is increasingly the case for fluid and ever-changing contemporary society, Möllering takes Giddens' concept of 'active trust' further to describe it as entailing suspension across a far greater gap of doubt between interpretation and expectation. A footing is provided for this momentous leap in attempts to become familiar with, and create reference points for, the unfamiliar (Child and Möllering 2000): 'the most important skill in practice is to find and reinforce a glimmer of familiarity in the unfamiliar context' (Möllering 2002, p.9). Julie Brownlie and Alexandra Howson (2005), in their exploration of Möllering's ideas in relation to reasoning about MMR vaccination, also note relations of familiarity as a basis for trust. Similarly drawing on Simmel's work however, they argue that suspension has to be understood as part of social relations occurring in particular social, political and institutional contexts.

2.5 Conceptually, in itself Möllering's interpretation/suspension/expectation argument poses a challenge to the simplistic cause-response political treatment of trust in an ethnically diverse society. Methodologically, it also poses a challenge to the dominant form of research on trust. In order to realise his conceptual framework empirically, Möllering calls for a move away from the trust inventories and survey-based research that characterises much work on the topic, towards an open-ended focus on meaning:

trust research's specific concern should be to find out whether a state of expectation towards other people's actions and intentions (the 'end' product) is favourable or unfavourable. Functional consequences are secondary (though important) to more general considerations ... trust research should aim to study instances of trust assuming idiosyncratic praxis and paying attention to the fine details of interpretation ... the starting point is the subjective 'reality' (context) as interpreted by the trustor; in other words 'good reasons' are extracted from rather than imposed on interpretation. (2001, pp. 415-416 - original emphasis) 
2.6 Our discussion here takes this approach but it also places it within the relevant wider political and institutional situation. Our study was not 'trust research' as such, in the sense that we did not have a focus on trust as a specific and prior aim of our exploration. Rather, trust and its process emerged as a key, recurring feature in the accounts of our interviewees, as well as forming a preoccupation of the political context that places such people as a 'problem' for trust in society generally. Our research participants' accounts, in effect, provide us with empirical demonstrations of the 'doing' of trust that allow us to reveal the process of 'active trust' in a specific socio-economic context.

\section{The Research Focus and Process}

3.1 The starting point for our research was an exploratory interest in the understandings of people who need interpreters in order to gain access to, and use of, health, legal, welfare and other services, in a situation where there has been little work that looks at this issue. ${ }^{[3]}$ Our narrative approach involved a focus on the meaning that people give to the stories that they tell about events, and was organised around placing people's experiences in the biographical, cultural and political context of their lives as a whole (see, for example, Gubrium \& Holstein 1998; Riessman 1992). Mark Robinson (2002) has argued that research into user views of interpreting services requires just such a context-sensitive methodology in order to address both structural and processual issues in communication. The advantage of our approach is that it enables the open-ended focus on meaning advocated by Möllering in exploring the process of trust, in particular linking structural inequalities in society with everyday interactions with formal and informal interpreters.

3.2 Semi-structured interviews were carried out with 50 people, comprising 10 interviewees from each of the following groups in their first language and dialect: Chinese and Kurdish people living in Greater London, and Bangladeshi, Gujerati Indian and Polish people living in Greater Manchester. These ethnic groups represent a variety of experiences of migration to and settlement in Britain around length of presence and levels of integration or marginalisation. The profile of each of these groups shapes their interaction with mainstream and community institutions (discussed further in Alexander et al. 2004, 2005). The Bangladeshi population in Greater Manchester have a highly localised concentration which has been adversely affected by a long process of deindustrialisation and social marginalisation - the focus of the political concern about ethnic segregation and low social trust in the wake of the disturbances of 2001 (see the Denham Report 2001). In contrast, the long-established Polish and Gujerati populations in Manchester have strong economic and community infrastructures and high levels of trust in these structures. The Polish population, however, has recently been augmented by Polish Roma arrivals, and they can be distrusted by the majority Polish group (as well as vice versa), and marginalized from economic and community infrastructures. The Chinese population in London represents another long settled minority ethnic group, but again differences are apparent between the established population of Hong Kong origin and more recent arrivals from mainland China, with different levels and types of economic and community infrastructure available within these groups. The Kurdish population in London represent recent arrival and settlement, despite attempts at dispersal, but do not have extensive local economic and community infrastructures, with particular trust concerns about the political allegiances of community provisions.

3.3 We were helped in our study by bilingual research assistants, who accessed research participants through a mix of channels - their own personal networks, a range of statutory and voluntary services, and community organisations. ${ }^{[4]}$ Our research assistants were themselves members of particular local ethnic communities, and a couple of them also worked as professional interpreters. Nonetheless, they often had to put much time and effort into establishing a trusting relationship with potential research participants and persuading them to be interviewed. While the resulting sample was not, of course, a demographically representative group, they covered a range of gender and age profiles. The sample also covered a range of social class profiles, albeit that this is a knotty issue in this context. While some of our research participants came from a poor material and educational background in their countries of origin and remained in deprived circumstances in Britain, others had been educated professionals and business people who found themselves downwardly mobile after arrival in Britain - their material capital diminished and their cultural capital not being convertible. Overall, our sample provides an illustrative depth of the kinds of experiences of people who need and use interpreters. ${ }^{[5]}$

3.4 The interviews encompassed a brief life history, addressing people's lives in their country of origin as well as their experiences in Britain. They then concentrated on encouraging a 'story telling' approach to instances when interviewees required interpreters in order to gain access to various services, drawing out specific issues concerning the implications of a lack of English language competence; locating and accessing interpreters from both formal and informal sources; who and what type of interpreter and interpreting they felt best served their needs; and their self-positioning and perception of others within this relationship. Our grounded analysis of the resulting material, after translation and transcription into English, was built around a thorough reading of each interview as a whole, and induction of recurring narrative themes and preoccupations within and across the accounts, rather than searching for issues that we had 
identified in advance. One of these recurring inducted themes was the issue of trust in people's understandings and experiences of needing and using interpreters. (A full report of the research findings and recommendations is in Alexander et al. 2004.)

\section{The Socio-Political Context for Trust}

4.1 As noted earlier, the concept of trust has featured with growing prominence in discussions about the state of modern society, related to concerns about social cohesion and order. There are arguments that lack of a routine trust in people generally and a sense of an unpredictable social environment results in a lack of abstract trust in experts and institutions, an undermining of general trust in local communities, and a retreat into personal trust in family and friends (Misztal 1996). Indeed, the British government has attempted to measure levels of trust in society and its relationship to social integration and co-operation, and civic participation (Home Office 2004; Performance and Innovation Unit 2002). There are also counter arguments, however, suggesting that a generalisable rationality for trust is a technocratic illusion, and indeed misses the point (Möllering 2001). These arguments about levels and processes of generalised trust map onto the political context concerning inverse links between ethnic diversity and social trust. In a situation where minority ethnic groups are posed as living 'parallel lives' to mainstream society (Denham Report 2001), it is notable that trust research has tended to overlook the views of the very people who are seen by some to comprise 'the problem' of decreased social trust.

4.2 Across the various minority ethnic groups participating in our research, people tended to hold different views on the trustworthiness of the society and particular communities in which they lived. These ranged along a continuum of generalised distrust, through contingent distrust and trust based on group membership or familiarity, to a more generalised trust.

4.3 Some of our interviewees expressed a great deal of general distrust, whether of the same ethnic group as themselves or not. They felt that their life experiences had led them to question the stability of society and the motives of others:

I think there is no safety and trust at all in the world. In Iraq, Saddam took the safety and trust. England is safe, no war, but you can't leave your children alone, there are too many problems. (Nisime, Kurdish woman);

I don't keep any friends. Everyone is deceiving, everyone is too smart, nobody gives any respect ... I only keep my children's company, that's it. (Shyamal Kotecha, Gujerati man).

4.4 For most others, however, trust - and therefore distrust - was contingent. This contingency could be organised around someone's membership of a particular ethnic category, but it could also be based on personal knowledge of someone:

I don't trust any of my neighbours because since I came here I tried to create friendships with them but all of them are bad and they don't show me any respect ... Sometimes I go to the Kurdish community centre and chat with my people and I feel like I was in my own country. Everyone speaks Kurdish and really I feel proud of myself and confident ... I can't mix with English speakers because they don't respect me. (Nedim, Kurdish man);

Trust is one thing you cannot understand by looking at people's face. Unless you interact and communicate with a person, you cannot possibly understand them. There are people who are good and bad in society, there are good and bad people around. (Maroof Khan, Bangladeshi man).

4.5 A few of our interviewees did evidence a generalised trust, however. These people often rejected ethnic group membership as a contingent basis for trust, and one cited the institutional 'codes' associated with abstract trust:

My near neighbour is White, also there are Pakistanis, and across the road there are Gujeratis. I can trust them all. (Suraj Gangani, Gujerati man);

I trust my neighbours and I don't feel unsafe in this area because I believe that [in Britain] democracy and human rights are above everything. (Hasan, Kurdish man).

4.6 For the people we interviewed, however, there did not appear to be any easy, deterministic relationship between a general sense of trust or distrust of the society and communities in which they lived, and the tendencies towards personal or abstract bases for trust in interpreters that we go on to explore in the rest of this article. For example, those who felt that they could trust people generally did not stand out from others in placing more faith in professional interpreters. Nevertheless, the contingent positions on trust in 
particular herald the qualities of familiarity in personal trust with interpreters, and attribution of particular characteristics to members of a group as a feature of abstract trust in professional interpreters. Before exploring these views in more detail, however, we turn to the functional conception of trust implicit in formal interpreting service provision.

\section{The Institutional Context: Professionalisation of Interpreting}

5.1 Alongside the current national policy emphasis on English language competence, the need to provide interpreters in order to address communication needs is increasingly being addressed by service providers. Several statutes are accompanied by explanatory memoranda and codes of practice that recommend this (Department of Health 2004, Saunders 1994). Interpreting services are located within local authorities, health services, the criminal justice and immigration services, the voluntary sector and the private sector, or partnerships of these. Within this provision, interpreters mainly work peripatetically, whether employed fulltime, part-time or sessionally. In addition to face-to-face provision, telephone services have been set up, and there are also experiments with tele-video links and touch screen kiosks. Despite such developments, formal interpreting provision is often in short supply (Baxter 1997; Netto et al. 2001; Yu 2000). People who need interpreters in order to access services often provide their own interpreters from among their informal networks.

5.2 There is a growing emphasis on professionalisation of the interpreting role, with recognised training and qualifications for interpreters. A key feature of this is the drawing up of codes or guidelines for standards of behaviour and ethical good practice in which the interpreter needs to be trained and accredited. For example, a National Register of Public Service Interpreters has been set up, and those registered are required to hold a qualification and follow a code of conduct. The Institute of Linguists Code of Professional Conduct includes: avoiding showing religious, racial, political or sexual prejudice; honesty about linguistic and specialist competence; carrying out work with complete impartiality; fidelity to meaning and register in interpreting; intervening only for the purposes of clarification and to correct misunderstanding; accountability for the work carried out; and a duty of complete confidentiality. Professional interpreters' knowledge of service structures and procedures, and written and spoken competence in specialist and informal terminology, and language transfer skills, are contrasted with the ignorance, incompetence and bias of untrained interpreters such as family and friends (Corsellis 1998; Shackman 1985).

5.3 Underlying the professionalisation of the role of interpreter is a functionalist assumption about the nature of trust, and so of 'trustworthy' interpreters. Trust in interpreters is best achieved and evidenced through an objective, specialist, regulated role. In other words, it assumes the efficacy of abstract trust, based on impersonal belief in the ability, intention and obligation of an expert or institution to perform the function that they are supposed to. This assumption about the functional potency of professionalisation is not, however, based on knowledge of what engenders trust for people who need interpreters themselves. Indeed, when researchers have addressed the issue, they have concluded that service users' preferences are uninformed and inappropriate, largely for linguistic technical accuracy concerns (for example, Rhodes \& Nocon 2003). There has been no work that focuses on the issue of trust in interpreters for people who need them, or the context for its particular expression. We will now explore this articulation in detail through four individual case studies. As we will show, professional constructions are not a complete match with the process of trust evident in the accounts of people who need interpreters

\section{Individual Case Studies of Trust in Interpreters}

6.1 From the 50 interview accounts available to us, we have selected illustrative case studies that represent the range of views across our sample. Such cases allow a demonstration of the 'idiosyncratic praxis' of trust in relation to accessing services with interpreters in people's accounts. They show the complexity of the social phenomena of trust, focusing in particular on the process of trust in contrast to confidence, and familiarity as the articulation of the 'suspension' between interpretation and expectation that Möllering indicates is involved in both personal and abstract trust, as well as the process of active trust when familiarity is absent. The case studies also provide us with the means for analytic generalisation, in order to re-engage both with conceptual discussion of trust and with its political context.

\section{Case 1: Dipon Ghosh, a Bangladeshi man}

6.2 Dipon had lived in Britain for around 40 years, since he came from Bangladesh in his mid-teens. He had brought his wife and daughter over from Bangladesh and, although he still felt strong emotional links with his family of origin, regarded himself as settled in Britain and in his local community. He generally trusted people in his area, and felt 'comfortable'. Dipon spoke only 'basic' English and mainly relied on his friends, who had previously been his source of finding employment, to act as interpreters for him. He felt that an interpreter was someone who had bi-lingual ability: 
[They] must understand what I am saying and explain my explanation. This is my opinion. There is no need to have a preference about whether it is a man or a woman or to look at their religion. It should be whoever understands and is capable of doing it.

6.3 Dipon acknowledged that service providers 'select capable people' as interpreters. But, for him, his friends offered him more than linguistic skill. When his friends interpreted, his trust in them was based on their depth of understanding of him as a person, arising out of familiarity with each other and the continuity of their relationship:

It helps me a lot and it gives me confidence ... I think if I take [a friend] then he or she will understand my feelings, and if [a service] gets someone he or she will outline the questions and answers and will not understand everything.

Nevertheless, Dipon did value the confidentiality that would be provided by using a professional interpreter: 'I can't say everything to my friends, if something is private and very personal.'

6.4 Dipon's case illustrates the distinction between trust and confidence in the case of personal trust. While he generally trusted people and felt that his friends had a crucial depth of understanding of him that inspired trust and went beyond what a professional interpreter (however capable) could offer, he still felt that there were risks in relation to confidentiality. Nonetheless, it was this perception of a depth of understanding as an aspect of familiarity that allowed him to cross the space between interpretation and the outcome of trusting these people to act as interpreters for him, suspending or putting aside the risks to his privacy. And it was the lack of that familiarity that meant that he often could not suspend himself from interpretation (capable people) to expectation (trustworthy people) in the case of using professional interpreters.

\section{Case 2: Di Wu, a Chinese man}

6.5 Di Wu had left China in his mid-teens to come to Britain, and had been in the country for three years. He shared a house with a group of older Chinese men who came from the same village as he did, and said that he had many friends also from his area of origin, including through his membership of a Chinese church group. He found employment through these networks, and his friends acted as interpreters when he needed them as he only spoke basic English:

We are very close friends and we always help each other when needed ... My friends are good enough, they will interpret for me ... During work, sometimes speaking English is unavoidable, or I may need help to buy something or solve some problem. Normally I take them out to tea in return ... The advantages [of using friends as interpreters] is that my friends will treat me sincerely and they will always tell me the truth and provide good suggestions.

While Wu preferred to rely on his friends as interpreters because of their emotional commitment and loyalty to each other, he had some concerns about confidentiality:

It is hard to handle the situation when I need to talk about private matters. I am shy about talking about private matters in front of my friends.

6.6 He also acknowledged that, for some occasions such as legal matters, his friends did not have the requisite knowledge and professional interpreters were necessary:

On the occasion of applying for identification, [my friends'] knowledge is not good enough to make things clear, so I have to pay professional interpreters ... When I go to the Home Office, I need lawyers to help me to get identification. Then I need interpreters since the lawyers are all British. The interpreters work for the lawyer's office.

Wu had not, however, found such professional interpreters as satisfactory as his friends because they lacked commitment to him as a person:

They give me a one sentence interpretation and it's usually hard to understand. They don't care whether you understand what they say. Even if I ask them, they won't repeat something or give me any further explanation ... I still prefer friends ... Professional interpreters have too many clients each day, they do not have the time and energy to please everyone.

6.7 Wu's case demonstrates a strong belief in personal trust. He cited commitment and loyalty, and a concern with his own best interests, as aspects of familiarity that were reasons for trusting his friends to act as interpreters. This was, nonetheless, tempered by his embarrassment about revealing private matters to them. While familiarity with his friends largely enabled him to suspend across to the expectation of 
trusting them to interpret for him, in some situations it did not allow him to cross from interpretation to outcome. When it came to facing formal systems involving expert knowledge, and where his future was at stake, Wu felt that he needed to trust to the skills of a professional interpreter. In such an instance, it was the expertise of a category of person that enabled the crossing of the space - albeit that he had to suspend personal commitment as an aspect of familiarity, and this lack rendered the experience unsatisfactory.

\section{Case 3: Jie Chun, a Chinese woman}

6.8 Chun had lived in Britain for around 20 years, arriving as a young woman to join her husband, and lived with him and their three, now adult, children. She had spent her childhood years in China, before moving to Hong Kong. Chun spoke very little English, and found employment and access to facilities within the Chinese community. She relied on being able to access Chinese-speaking health service personnel:

Someone told me that there is a Chinese doctor in the GP surgery, so I could go and register with him ... He speaks Chinese, but he is Malaysian. There are some Chinese, they're Chinese looking but they can't speak Chinese. Once I went to a hospital, a Chinese doctor talked to me. I told him 'no English', but he couldn't speak Chinese either! ... Now there are many Chinese staff in the hospital. Sometimes I ask a nurse to interpret for me, they are all from Malaysia.

6.9 Failing this, Chun sometimes had to rely on her friends or her daughter to act as interpreters for her. She trusted them personally, but not their skill and expertise, so she preferred a professional interpreter:

[My friends and daughter] do not know how to interpret some medical words since they do not study medicine. Because of this, I always ask my family doctor to ask for the interpretation service for me and when I go to the hospital the interpreter can do the job for me. The interpreter is more professional. Their language ability is better. I prefer these professional interpreters.

6.10 The main drawback to professional interpreters, though, was that she was unable to establish a continuous relationship with them, involving depth of knowledge, and this had an impact on her trust:

The interpreters are normally very busy and I do not have many chances to chat with them. Normally an interpreter can only work an hour for each appointment. If the time is up, they will rush to the next appointment. I have never had a chat with them. They are normally late for the appointment because they need to take a bus or other transportation ... I am telling you one thing. I have been to hospital many times but the interpreter is a different person every time. They do not know my situation, they do not know what disease I have. Even if I met an interpreter who I had met before, they would not remember me. The reason is that they go to different hospitals every day and work for many people, they cannot remember each individual. I've been to hospital more than ten times and there is only one interpreter who has worked for me twice. So it is impossible to make them friends ... I have to trust the interpreter [when I don't know them], there is nothing I can do.

6.11 Chun represents another case of strong abstract trust. She first sought to furnish herself with a health care professional who spoke her language, and she trusted these people to do their job because they were professionals. If this was not possible, she was more trusting of a professional interpreter in the context of her health care than she was of her friends or family. It was the specialist role of professional that provided a reason for trust, and their expertise allowed her to cross from interpretation to expectation. But this is not confidence, because Chun was unsure about the time that the professional interpreter would arrive and, more importantly, these people had no continuous knowledge of her and her case. Thus the suspension was not passive trust; it was a case of actively 'having' to trust. A smaller leap or suspension would be provided if Chun could build a more personal relationship with her professional interpreter.

\section{Case 4: Mrs. Topolska, a Polish woman}

6.12 Mrs. Topolska had been living in Britain for about three years. She had come with her husband and three young children, but her husband had recently moved out of the household and she felt that particular people from the local Polish church and club were supporting her through a difficult time. Mrs. Topolska worked with English people in a job found through her Polish networks, but said that her ability to understand and speak English was limited. She had Polish friends who spoke good English, who she had called upon, and were happy to help her out with interpretation. Nevertheless, perhaps because of her personal situation, Mrs. Topolska was very concerned about confidentiality in trusting someone to interpret 
for her, and in this respect she said she preferred a professional interpreter who was not a member of her local Polish community. She also felt that the quality of objectivity in a professional interpreter was important:

There are people who only interpret so that they can gossip about people, but there are people who want to help... I know what people at the Polish club are like. I know from day-today who I can ask and who I can't. I know that. I stay away from those people ... I think that on a day-to-day basis it is better that the interpreter should not be someone you know. Noone you know, so that they can be objective, so that he can interpret. So if it was someone I knew, she would interpret everything from my point of view. It is better to use someone you don't depend on, who is neutral, and that he interprets honestly. So that he did not take sides. I think on a day-to-day basis that the Polish interpreter should start from zero, so that we did not know him ... All my friends will always take my side, and it has to be someone objective who sees you for the first time. She would come and interpret and then say goodbye.

6.13 Mrs. Topolska did know a professional interpreter who she had used over several years, and whom she trusted, but believed - somewhat wistfully, it seems - that this familiarity could compromise the interpreter's professional status in her particular circumstances:

The interpreter who was with us all the time knew me and my husband very well, even to the extent that we became friendly. So when I mentioned I had these problems, marriage problems, I mentioned it to her. I don't think she would want to take sides. I know she likes me. She likes my husband. She does not want to get involved in this. I know she could because she is registered everywhere ... She wants to remain neutral and not take sides. She said she was too close to us ... I trust her and never came across a situation where I did not. She knew everything. She never said anything she shouldn't have and she is an honest kind of woman.

6.14 Mrs. Topolska's case involves an in principle adherence to abstract trust. She strongly stated that professional codes of confidentiality and objectivity were reasons for trust, and further that it was a categorical (definitely not a personal) relationship that allowed her to cross to expectation. In contrast, the familiarity and bias of friends did not provide a firm footing for suspension (although familiarity did allow her to identify those in her local community who she could not trust). Yet there is an ambivalence here. While the codes and skills of abstract systems still reduce the space and engender trust, Mrs. Topolska has in fact had a personal, not merely categorical, relationship with a professional interpreter. One cannot help thinking that Mrs. Topolska would really like her professional friend to fling objectivity to the winds, and that she would be just as enabled, if not more so, to cross from interpretation to expectation.

\section{Discussion of the Process of Trust}

7.1 It is important to bear in mind that most people who need and use interpreters are in a position of relative powerlessness - both in relation to particular situations and in relation to the wider 'host' society and this sense of dependence and disadvantage will be an important factor in underpinning the relationship between individuals and interpreters, and in the articulation of trust. Within this, some of our research participants were in a more disadvantaged position than others. For example, some could draw on family, informal and formal community networks made up of well-educated professional and business people who spoke fluent English and were used to dealing with services and systems, while others had no such resources. Furthermore, women often relied on immediate and extended family or community institutions, such as church or temple, for social networks, interpreting and other support, while men tended to have more fluid and wider networks of friends (Alexander et al. 2005). Nonetheless, all the people who took part in our research expressed feelings of powerlessness, marginalisation and dependence in needing to rely on someone to interpret for them.

7.2 Most of the people in our research had used family and friends as interpreters at some time so that they could access services, and most preferred and trusted them over professional interpreters. In other words, there was a marked tendency towards exercising personal trust. In this sense, while our foregoing case studies are representative of the range of possible views to be found across our sample, two of them (Mrs. Topolska and Jie Chun) are not characteristic of the predominant perspective on who to trust to act as an interpreter among the sample (though they are representative of the minority who demonstrated abstract trust). Nonetheless, they are typical of the processes of trust in terms of the relationship between interpretation (reasons) and expectations (outcomes), and of what fills the space between them (the process of trust) in the case of needing interpreters to access services.

7.3 From people's accounts of the reasons for personal trust - for trusting family, friends and other known 
members of their community to act as interpreters for them, across the different ethnic groups - we can identify a number of interlinked reasons forming the basis for this trust. These are that the person acting as interpreter has a relational status as family member or close friend, that there is familiarity with the person and continuity of relationship with them; that they are felt to have an in-depth of knowledge of each other; and that they have an emotional commitment and loyalty to each other. These reasons do not become confidence, however, as we saw for Dipon Ghosh. Further, they do not always allow for risks to privacy and risks from linguistic lacks to be suspended, and the leap from interpretation to expectation in terms of the outcome of trusting that familiar person to act as an interpreter. This was the case for Di Wu in facing formal legal procedures. Familiarity as part of personal trust cannot always enable suspension.

7.4 Even if our sample overall did not prefer to use and trust professional interpreters, people identified several qualities they expected of them, which formed reasons for trusting those who fill the role. In particular, they referred to professionals' adherence to codes of good practice, including confidentiality; to their skill and expertise, including bi-lingual competence and exactness, knowledge of systems and jargon; and to their lack of bias, in the sense of holding no hidden personal or institutional agenda. In other words, people could draw on expectations that a professional interpreter would act in a trustworthy way, exercising their skill and expertise in a fitting and confidential manner, because of the standards of conduct associated with their role. Both Jie Chun and Mrs. Topolska illustrate that these are reasons that enabled them to cross the space between interpretation and expectation, suspending other sorts of risks. They still hankered after elements of personal trust to be involved, notably familiarity, in order to alleviate their sense of the risk that they were taking in relying on a professional interpreter to fulfil their obligations.

7.5 Our case studies, and indeed everyone in our sample, demonstrated 'active trust' in needing to suspend across a large gap between interpretation and expectation. They were taking crucial risks and evaluating who, and whether or not, to trust in a range of situations where they needed interpreters in order to access services. Ironically, in the light of such arguments, our interviewees are themselves both part of the risks perceived to be posed by ethnic diversity to generalised trust within British society, and subject to high degrees of uncertainty and incomplete knowledge in this context in not being fluent in the dominant language of English and needing to trust others to communicate. From a marginalised position, they have to struggle far more to find a 'glimpse of familiarity in the unfamiliar context' than the majority of British society. Indeed, active trust is not necessarily the mark of the supreme agentic actor; it can be a feature of its lack. Fran Tonkiss remarks that 'having to rely on trust is an index of a relative lack of ... social or economic power' $(2004$, p. 22). The people taking part in our research did not have the choice whether or not to rely on an interpreter, and sometimes not even who to trust to act as an interpreter. Jie Chun's comment that 'I have to trust' is salutary. Distrust is active too, and as Niklas Luhmann (1979) argues, it can be a healthy and functional alternative to trust.

\section{Strategies for Managing Distrust in Interpreters}

8.1 Accounts of negative experiences of professional and other service-based interpreters were not unusual in our research. The people we interviewed had a number of ways of managing their uncertainties about whether or not someone was trustworthy and evaluating the risk that they were taking in trusting them to act as their interpreter. For the most part, people attempted to monitor the situation using evaluation of qualities that respectively form part of personal trust and abstract trust.

8.2 In terms of the qualities underlying personal trust, people attempted to assess their interpreters' emotional and non-verbal signals as the interpretation took place:

For instance, when I speak or try to ask someone something, if the interpreter smiles at me then I feel that he doesn't hate us, so I gain confidence. But if the interpreter looks at me badly, then I understand that he doesn't like us. (Tuncer, Kurdish man).

Interpretation over the telephone could cut across attempts to monitor the interpretation and assess its trustworthiness on this visual basis, and the two people in our sample who mentioned that they had used telephone interpreting services both found the process unsatisfactory.

8.3 In terms of the qualities underlying abstract trust, people could attempt to draw on any limited English language skills they had to evaluate the interpreter's expertise in this respect. If they could not do this form of monitoring themselves, then the people we interviewed might enlist their family or friends, or check one interpretation against another. A good example of this is Hasret, a Kurdish man, in talking about his experiences in applying for asylum. His distrust of his interpreter during the court hearing had been aroused when he had said 'September' and heard it interpreted into English as 'November'. He had corrected this misinterpretation and, from then on, suspected that the interpreter had turned against him and had not represented his situation correctly: 
After I received the refusal [of my asylum application] one of my friends interpreted my verdict to me. I found many things were the opposite of what I had said. This is very important. I can tell you a tragic story and you can interpret it as a comic story ... I lost my trust in [interpreters]. Now if I have a letter or something, I ask two different people to interpret it for me. Because the interpreter can finish your life if he is bad. Like me, I got refused because of the interpreter.

8.4 Hasret's lack of trust in professional interpreters meant that he preferred to turn to relatives and friends, rather than rely on professional interpreters, despite some misgivings about confidentiality. In this sense, reasons for distrust were just as important in the suspension involved between interpretation and expectation, as were reasons for trust.

\section{Concluding Issues}

9.1 This paper has provided an in-depth examination of the process of trust through praxis, in a context where trust emerged as a key feature in the accounts of people who need interpreters in order to access services. In essence, we found that the embodiment of trust in an interpreter is either a family member or friend who has professional skills and expertise, and adheres to professional codes of good practice, or a professional interpreter who fulfils the obligations inherent in their role and is a familiar person. In the case of needing interpreters in order to access services, it is indeed the case, as Giddens (1994; 1998) has argued, that personal trust involving aspects comprising familiarity is required as a supplement to abstract trust. Ironically, however, the very qualities that might have moved people's abstract trust closer to confidence are eschewed by the trends involved in the professionalisation of the interpreting role. Professionalisation is being developed functionally around training and codification. While many of the features of this professionalisation chime with interpretations that can be called upon to cross the constitutive space of trust to expectation, such as specialist competence, fidelity to meaning and confidentiality, other features provide a potential collapse into a void of distrust. In particular, impartiality does not provide a firm suspension for trust, in contrast to interpretations that the person who needs the interpreter is having their interests put first. The familiarity and commitment that most often provided a firm footing for suspension for the people in our research is not part of the impersonal process of trust invocation in the professionalisation of interpreting, and this is compounded by the peripatetic structure of service provision.

9.2 There are caveats to this overall thrust of the process of trust in interpreters in order to access services, however. Just as there is no easy relationship between generalised trust and specific trust, familiarity and commitment as interpretation do not always allow the suspended crossing to the outcome of trust in the familiar and committed person. Trust is contingent and subject to individual context. But in the case of people who need interpreters to access services, it is also a praxis that takes place in a distinct sociopolitical context, articulated by people who are positioned in particular ways in relation to their (non)membership of society as a whole. Like Brownlie and Howson (2005), we argue that a focus on interpretation/suspension/expectation in understanding trust is helpful but it is crucial that it is situated in the social relations of its political and institutional context. In particular, asymmetrical social differentiation and specific issues of power need to inform trust research. It is ironic that the people who are required to risk the crossing of the constitutive space of trust in interpreters in order to use the mainstream services provided by society - with little attention to their views on the best means of achieving this - are the very people who are regarded as putting wider social trust at risk through their 'self-induced' marginalisation from citizenship practices.

\section{Notes}

${ }^{1}$ As part of this, Möllering outlines and addresses debates about the extent to which trust is a rational, cognitive or emotional, faith-based process, which we do not rehearse here.

2 Throughout this article we put the conceptual notion of 'interpretation', representing reasons to trust, in italics in order to distinguish it from our substantive topic of 'interpretation', as the process of translation across languages.

3 The 'Access to Services With Interpreters: User Views' project was funded by the Joseph Rowntree Foundation, and we are grateful to them for their support.

${ }^{4}$ Accessing interviewees, the interviews themselves, and their translation and transcription into the English language were carried out by Usha Kanani (Gujerati), Liu Zhuang (Chinese), Mohib Miah (Bangladeshi), Anita Sam (Chinese), Bogusia Temple (Polish), and a Kurdish research assistant who wishes to remain 
anonymous. While one of them is an academic and an author of this article, the others work in the business sector and in service delivery in the voluntary and statutory sectors. We fully acknowledge their contribution to this article.

5 The names we use for our research participants are pseudonyms provided by the researchers who undertook the interviews. The quotes used are verbatim from the transcripts that they provided and are not always in standard, grammatical English. See Temple (2005) for a discussion of the politics of translation.

\section{References}

ALEXANDER, C., EDWARDS, R. and TEMPLE, B., with KANANI, U., LIU, Z., MIAH, M. and SAM, A. (2004) Access to Services With Interpreters: User Views. York: Joseph Rowntree Foundation.

ALEXANDER, C., EDWARDS, R. AND TEMPLE, B. (2005) 'Contesting Cultural Communities: Language Ethnicity and Citizenship', unpublished paper under submission.

BACK, L., KEITH, M., KHAN, A., SHUKRA, K. and SOLOMOS, J. (2002) 'New Labour's white heart: politics, multiculturalism and the return of assimilation', Political Quarterly, Vol. 73, No. 4, pp. 445-454.

BAXTER, C. (1997) 'The Case for Bilingual Workers Within the Maternity Services, British Journal of Midwifery, Vol. 5, No. 9, pp. 568-572.

BAUMAN, Z. (2000) Liquid Modernity. Cambridge: Polity Press.

BECK, U. (1999) World Risk Society. Cambridge: Polity Press.

BROWNLIE, J. and HOWSON, A. 'Leaps of Faith" and MMR: An Empirical Study of Trust', Sociology, Vol. 39, No. 2, pp. 221-240.

CHILD, J. and MÖLLERING, G. (2000) 'The Development of Organizational Trust in the Chinese Business Context', Research Papers in Management Studies No. 34, Cambridge: Cambridge University Press.

CORSELLIS, A. (1998) Working Across Language and Culture: Report and Recommendations. West Midlands Probation Service.

CRICK REPORT (2003) Life in the United Kingdom, Report of the Advisory Group on Citizenship. London: Home Office.

DENHAM REPORT (2001) Building Cohesive Communities. London: HMSO.

DEPARTMENT OF HEALTH (2004) Guidance on Developing Local Communication Support Services and Strategies. London: Department of Health Equalities Strategy Unit.

FOX, A. (1974) Beyond Contract: Work, Power and Trust Relations. London: Faber and Faber.

FRANKEL, S.H. (1977) Money: Two Philosophies. Oxford: Basil Blackwell.

GIDDENS, A. (1994) 'Risk, Trust, Reflexivity', in U. Beck, A. Giddens and S. Lash (eds) Reflexive Modernisation. Cambridge: Polity Press.

GIDDENS, A. (1998) The Third Way: The Renewal of Social Democracy. Cambridge: Polity Press.

GOODHART, D. (2004) 'Too diverse?', Prospect, February. Retrieved on-line on 30.4 .04 at http://www.prospect-magazine.co.uk.

GUBRIUM, J. and HOLSTEIN, J. (1998) 'Narrative Practice and the Coherence of Personal Stories, Sociological Quarterly, Vol. 31, pp. 163-187.

HOME OFFICE (2004) Strength in Diversity - Towards a Community Cohesion and Race Equality Strategy , Consultation Paper. Retrieved on-line on 23.6.04 at http://www.homeoffice.gov.uk.

LUHMANN, N. (1979) Trust and Power: Two Works by Niklas Luhmann. Chichester: John Wiley.

MISZTAL, B. (1996) Trust in Modern Societies: The Search for the Bases of Social Order. Cambridge: Polity Press.

MÖLLERING, G. (2001) 'The Nature of Trust: From Georg Simmel to a Theory of Expectation, Interpretation 
and Suspension, Sociology, Vol. 35, No. 2, pp. 403-420.

MÖLLERING, G. (2002) 'Traditional, Institutional and Active Trust: Just Do It!?', paper presented to the European Academy of Management conference, Stockholm, Sweden, 9-11 May. Retrieved on-line on 3.4.05 at http://www.sses.com/public/events/euram/complete_tracks/trust_within_organizations/mollering.pdf.

NETTO, G., GAAG, S. and THANKI, M. with BONDI, L. and MUNRO, M. (2001) A Suitable Space: Improving Counselling Services for Asian People. Bristol: Policy Press/JRF.

PEFORMANCE AND INNOVATION UNIT (2002) Social Capital: A Discussion Paper. London: Cabinet Office.

PUTNAM, R.D. (2003) keynote address to the Families \& Social Capital ESRC Research Group 'Ethnic Diversity and Social Capital' event, ESRC Social Science Week, The British Academy, 24 June.

RIESSMAN, C.K. (1992) Narrative Analysis. London: Sage Publications.

RHODES, P. and NOCON, A. (2003) 'A Problem of Communication? Diabetes Care Among Bangladeshi People in Bradford', Health and Social Care in the Community, Vol. 11, No. 1, pp. 45-54.

ROBINSON, M. (2002) Communication and Health in a Multi-Ethnic Society. Bristol: Policy Press.

SCHUSTER, L. and SOLOMOS, J. (2004) 'Race, Immigration and Asylum: New Labour's agenda and its consequences', Ethnicities, Vol. 4, No. 2, pp.267-300.

SAUNDERS, M. (1994) Issues and Practice in Interpreting: Guidance Notes. London: London Interpreting Project.

SHACKMAN, J. (1985) The Right to be Understood: A Handbook on Working With, Employing and Training Community Interpreters. Cambridge: National Extension College.

TEMPLE, B. (2005) 'Nice and Tidy: Translation and Representation', Sociological Research Online. Volume 10, Issue 2, http://www.socresonline.org.uk/10/2/temple.html.

TONKISS, F. (2004) 'Trust and Social Capital', in J. Franklin (ed.) Politics, Trust and Networks: Social Capital in Critical Perspective, Families \& Social Capital ESRC Research Group Working Paper No. 7. London: London South Bank University.

YU, W.K. (2000) Older Chinese People: A Need for Social Inclusion in Two Communities. Bristol: Policy Press/JRF.

ZUCKER, L.G. (1986) 'Production of Trust: Institutional Sources of Economic Structure 1840-1920', in B.M. Straw and L.L. Cummings (eds) Research in Organisational Behaviour. Greenwich: JAI Press Inc. 